\title{
ElDeporte y la Televisión: El papel del profesional de Educación Física Sport and Television: the role of the professional of Physical Education
}

\author{
Milena Avelaneda Origuela, Cinthia Lopes da Silva \\ Universidad Metodista de Piracicaba (Brasil)
}

\begin{abstract}
Resumen: Este trabajo tiene como objetivo analizar la relación existente entre el deporte y la televisión, e identificar el papel del profesional del área de Educación Física en relación al deporte televisivo. Los diferentes medios de comunicación de masa (MCM) producen discursos e imágenes relacionadas al deporte, atribuyéndole a este elemento de la cultura, una serie de significados. Específicamente, ver el deporte a través de la televisión, es muy diferente de verlo en estadios y gimnasios, porque la producción televisiva está restricta a las jugadas y escenas previamente elegidas y seleccionadas por periodistas y productores de la información. Como procedimientos metodológicos, se realizó una revisión bibliográfica de carácter cualitativa, así como un análisis textual, temático, interpretativo y crítico de los libros de estudiosos del Ocio, de la Comunicación y de la Educación Física. Las conclusiones son las siguientes: Al transmitirse el deporte por la televisión, éste es transformado en un «telespectáculo». Es en este proceso que se hace fundamental el papel desempeñado por el profesional de Educación Física, así como sus conocimientos. Este profesional, basado en la perspectiva de la Educación para el Ocio, será capaz de facilitar en sus alumnos el acceso al conocimiento propio del área, y el que éstos alcancen un nivel superior o inventivo de comprensión. De esta manera la intervención pedagógica realizada en la educación formal será fundamental para que dichos sujetos tengan acceso a elementos teóricos tales que les permita realizar una lectura competente del deporte difundido por el conjunto de medios de comunicación, y con ello disfruten de sus momentos de ocio con calidad.
\end{abstract}

Palabras clave; Deporte; Ocio; Medios de Comunicación; Cultura.

Abstract: This paper has the objective of analyzing the relationship between sports and television, and identifies the role of the professional who acts in the field of Physical Education related to sport on television. The media institution produces discourses and an image related to sports and attributes a group of signifiers to this cultural element. Watching sport on television is different from watching them in a stadium or a gymnasium. This occurs because the televise production is restrict to the passes and scenes chosen previously by journalists and producers. As methodological procedures, it was made bibliographical review of qualitative type and also, thematic, textual, interpretative and critical analysis of the books written by scholars in the field of Leisure, Communication and Physical Education. The conclusions are: sport, when it is showed by television, it is transformed into entertainment. During this process, the role of the professional of Physical Education is essential to mediate knowledge. The teacher, based on the perspective of education for leisure, can help students to have access to the knowledge so they can reach superior and inventive level of comprehension. Accordingly, pedagogical mediation realized in formal education will be essential so that the subjects have access to theoretical elements for a qualified reading of the sport showed by media, thus, they can enjoy their moments of leisure with quality.

Key words: Sport; Leisure; Mass Media; Culture.

\section{Introducción}

Este trabajo tiene como objetivo analizar la relación existente entre el deporte y la televisión e identificar el papel del profesional del área de Educación Física en relación al deporte televisivo. Los diferentes medios de comunicación masiva producen discursos e imágenes relacionadas al deporte, y le atribuyen una serie de significados a este elemento de la cultura. Ver el deporte por la televisión es diferente de verlo en estadios y gimnasios, porque la producción televisiva está restricta a las jugadas y escenas previamente elegidas y seleccionadas por periodistas, productores de informaciones y de imágenes transmitidas por la televisión. Esta producción tiene como característica la difusión de informaciones listas, de rápida asimilación, que dificultan el que los telespectadores realicen sus propios cuestionamientos.

Se hace fundamental una acción educativa en el ámbito de la educación formal, para que los sujetos puedan realizar una lectura competente del deporte difundido a través de los medios de comunicación de masas, y puedan disfrutar de sus momentos de ocio con calidad, siendo así posible el seleccionar y comprender críticamente los contenidos a los que ellos acceden. La perspectiva de una educación para el ocio es una posibilidad teórica existente para interceder pedagógicamente en el ámbito de la educación formal, y tiene como propósito hacer viable en dichos sujetos el poder transformar la información en conocimiento y, en este caso propiamente dicho, el transformar la información deportiva en conocimiento.

Esta perspectiva, por lo tanto, instiga en los espectadores, oyentes y lectores de las noticias deportivas que viven en el contexto de la sociedad globalizada, la posibilidad de creación y de atribución de nue-

Fecha recepción: 15-09-11- Fecha envío revisores: 16-09-11 - Fecha de aceptación: 03-04-12 Correspondencia: Milena Avelaneda Origuela

Rua Governador Pedro de Toledo, 632 - Centro

13400-066 Piracicaba/SP - Brasil

Email: djmilenasound@ hotmail.com vos significados al deporte. Delante de lo expuesto, este trabajo tiene como cuestionamientos: 1. ¿Cómo se realiza el proceso de difusión del deporte a través de la televisión? 2. ¿Cuál es el papel del profesional de Educación Física en relación al deporte televisivo? Como procedimientos metodológicos se realizó una revisión bibliográfica de carácter cualitativo, así como un análisis textual temático, interpretativo y crítico de los libros de estudiosos del Ocio, de la Comunicación y de la Educación Física, como: Pierre Bourdieu, John B. Thompson, Joffre Dumazedier, los españoles Roberto Aparici, Julio Tello Dìaz y Joaquín Marín Montín, y los autores brasileños Mauro Betti y Nelson Carvalho Marcellino.

Se pretende que este trabajo contribuya a la ampliación del diálogo entre las diferentes áreas del conocimiento, y a la revisión de conceptos de parte de los profesionales que actúan en el ámbito de la Comunicación, Deporte y Ocio.

\section{Antecedentes}

\subsection{La difusión del Deporte en la televisión}

Bourdieu (1997), en el estudio sobre la televisión, intentó comprender las relaciones de poder que constituyen ese campo. Para el referido autor, un campo es:

(...) un espacio social estructurado, un campo de fuerzas - hay dominantes y dominados, hay relaciones constantes, permanentes, de desigualdad que ejercen en el interior de ese espacio - que es también un campo de luchas bajo el objetivo de transformar o conservar el campo de fuerzas. Cada uno, en el interior de ese universo, comete en su competencia con los otros la fuerza (relativa) que detiene y que define su posición en el campo y, por consecuencia, sus estrategias (p. 41).

Siguiendo esta línea, la televisión puede ser estudiada como: un campo en el cual se presenta una competencia económica entre los distintos canales de televisión o periódicos (tanto alrededor de los lectores como de los mismos auditores), un campo en el que se da la 
búsqueda por alcanzar las cuotas que el mercado exige, un campo donde se realiza concretamente la competencia entre los sujetos que participan de este medio (llámese periodistas, gente que se encuentra por detrás de la elaboración de la información, gente que se encarga de la reputación profesional de este medio), sin que necesariamente sea una lucha puramente económica, pero sí sometida a los órganos de prensa que, a su vez, firman determinada posición en relación a la fuerza económica y simbólica (Bourdieu, 1997).

A fines de la década de los 40 e inicio de los 50, el universo de los ciudadanos se transformó, y la tecnología y el lenguaje de la imagen pasaron a hacer parte del contexto audiovisual de las personas (Aparici, 2005).

De acuerdo con Aparici (2005), debido al surgimiento del marketing y el desarrollo del lenguaje televisivo «a mayoría de las personas pasó a tener más conocimiento del mundo virtual que del mundo real» (p.16). No obstante, el referido autor destaca que esta visión del mundo depende de la ubicación en que se encuentre este individuo. Por ejemplo, un habitante de Guinea tuvo poquísimas posibilidades de conocimiento del mundo por medio de la imagen, en relación a un habitante de Nueva York, Sao Paulo o Madrid. Con esto reforzamos la idea de que la tecnología permite ampliar el contexto social. En Brasil, por ejemplo, el uso de la televisión se extiende a casi un $90 \%$ de la población. De tal forma que los brasileños pasan a tener conocimiento del mundo a través de la televisión. Con el transcurso del tiempo prolifera el número de canales de televisión, lo que permite que una buena parte de la población tenga acceso a la información, y generalmente de forma manipulada (Aparici, 2005).

Con relación al deporte, Pierre Bourdieu (1983) afirma que éste es un espacio estructural de prácticas sociales, donde las posiciones de los agentes sociales se establecen a partir de la competencia y de la disputa por objetos y elementos de distinción. La mercantilización interfiere en la definición de los tipos de capital atribuido a determinadas prácticas, decretando así relaciones entre la oferta y la demanda de los deportes (Marchi Junior, 2005).

Sobre cómo es la comunicación en la televisión, Bourdieu (1997) afirma que hay un eslabón entre el pensamiento y el tiempo. En la televisión hay una relación entre pensamiento y velocidad, y nos propone una pregunta: «iSerá que la televisión, al dar la palabra a pensadores que supuestamente piensan en velocidad acelerada, no está condenada a tener sólo fast-thinkers, o sea, pensadores que piensan más rápido que su sombra...?».

La cuestión discutida es que esos telespectadores piensan a través de «ideas hechas». Es como si esto estuviera listo, resuelto. La comunicación es instantánea, de cierto modo ella no existe (Bourdieu, 1997). Los discursos, las noticias, llegan ya listas por la televisión, tan rápidas como una comida rápida, un fast-food cultural, y no tenemos tiempo de pensar o analizar lo que vemos.

Esas ideas pueden ser extremadamente enriquecedoras en un debate sobre cómo se construye la información difundida por los MCM (medios de comunicación de masa) destacando el «juego» de poder, sobre todo simbólico, existente entre los sujetos participantes de determinado campo. En el texto «Los Juegos Olímpicos: programa para un análisis», Bourdieu (1997) señala elementos constitutivos en la transmisión de los Juegos Olímpicos, remitiendo al lector hacia el «detrás de cámaras». Los comentarios realizados pasan por el papel de los atletas y su nación, la comercialización de las imágenes y discursos sobre los Juegos, las negociaciones que envuelven emisoras televisivas, y el Comité Olímpico Internacional (COI).

El autor afirma que hay una «transmutación simbólica» entre atletas y nación. El espectáculo televisivo transforma la competición deportiva entre atletas provenientes de las diferentes naciones del planeta en un enfrentamiento entre campeones, entre combatientes enviados por ellas. Parece que la posibilidad de participar y de hacer lo mejor posible para un buen desempeño como representantes de sus países, como muchas veces se anuncia, es un factor de menor importancia delante de la demostración de poder entre las respectivas naciones, por medio de los atletas.
Esa «transmutación simbólica» es como un cambio de foco, y nos da la oportunidad de analizar la construcción social del espectáculo olímpico, de las propias competiciones y sus manifestaciones (desfiles de apertura y cierre). Podemos analizar la producción de la imagen televisiva con sus anuncios publicitarios como un producto comercial y que aparece en los horarios de gran audiencia, y tomar por modelo el conjunto del campo de producción de los juegos olímpicos como espectáculo televisivo, como «instrumento de comunicación», o sea, el conjunto de relaciones entre los agentes y las instituciones comprometidas en la competencia por la producción y comercialización de las imágenes y de los discursos sobre los juegos (Bourdieu, 1997).

Cuando Bourdieu (1997) destaca esa relación entre agentes comerciales y las instituciones televisivas, nos habla sobre el Comité Olímpico Internacional. Este órgano se ha convertido progresivamente en una gran empresa comercial, dominada por dirigentes deportivos y representantes de las grandes marcas industriales (Adidas, Coca-Cola, etc.), y que controla la venta de los derechos de transmisión de los Juegos, de los auspicios, de las ciudades donde los Juegos se realizarán, en fin, un conjunto complejo de relaciones sociales que están involucradas en la transmisión de los Juegos Olímpicos.

Culturalmente, cuando hablamos de deporte acabamos asociándolo a los Juegos Olímpicos. Pero, ¿qué son realmente los Juegos Olímpicos, y cuál es su relación con la televisión? Entendemos por Juegos Olímpicos un evento deportivo donde ocurre el enfrentamiento de atletas de todo el mundo, con las competiciones propiamente dichas y sus rituales, como los desfiles por equipos y entrega de medallas con banderas e himnos nacionales (Bourdieu, 1997).

La televisión nacional da mayor espacio a un atleta o práctica deportiva en la medida en que ellos sean capaces de satisfacer el orgullo nacional; la representación televisiva, aunque aparezca como un simple registro, transforma la competición deportiva en un enfrentamiento de campeones. Los deportes y modalidades que aparecen en los Juegos dependen de las preferencias de los públicos nacionales por determinados deportes, y del éxito y satisfacción a su nacionalismo (Bourdieu, 1997).

En la televisión sobresalen las competiciones nacionales e internacionales, y se las transmite como si se tratara de una guerra entre naciones, y con ello se contribuye grandemente a que dichas competencias se intensifiquen, lo que da como resultado la aparición de una política deportiva que se presenta entre países, orientada hacia los éxitos internacionales, la explotación simbólica y económica de las victorias, y la industrialización de la producción deportiva que implica el recurso al doping y las formas autoritarias de entrenamiento (Bourdieu, 1997).

Otra referencia a los estudios de los medios de comunicación es la producción del sociólogo inglés Thompson (2000). El autor afirma que el desarrollo de la industria de los medios comunicativos, intensificado sobre todo a partir del siglo XIX, es una transformación que está interrelacionada a la construcción de la ideología de la cultura moderna. El autor comenta que los primeros estudiosos que discutieron el tema de la ideología fueron los autores de la llamada «Escuela de Frankfurt». Para ellos, las ideas difundidas acerca del arte y de la literatura por la Industria Cultural se transformaban en mercancías, en formas ya listas, acabadas, reproduciendo una lógica que transformaba las producciones humanas como el arte en producto, distribuido por técnicas de reproducción, y en este proceso se podría estudiar todo un sistema social.

Para Thompson (2000), el problema de la concepción de ideología de algunos autores de la Escuela de Frankfurt es la concepción de ideología tomada como un tipo de «cemento social», como si los sujetos, cuando reciben los mensajes difundidos, se prendieran a la orden social, siendo ésta siempre más rígida y resistente a los cambios. Otro punto de su crítica es la ausencia de evidencias de que la recepción de los productos de la industria cultural lleve a los individuos necesariamente a la reproducción de la realidad social. Esas críticas se atribuyeron a los estudios iniciales de la Escuela de Frankfurt, desarrollados, sobre todo por Adorno y Horkheimer.

Con relación a la recepción de los productos de la industria cultural, Thompson (2000) nos llama la atención al término «comunicación 
masiva». Por tratarse de una transmisión de mensajes de sentido único, y, en el caso de la televisión, del transmisor para el telespectador, donde el receptor tiene poca posibilidad de contribuir con el contenido que va a presentarse, sería más apropiado hablar de «transmisión»o «difusión».

\section{Estado actual del tema}

3.1. La transformación del deporte como un «Telespectáculo»

En los últimos años nos hemos dado cuenta de un cambio en relación a este modo de transmisión. En algunos casos de comunicación de masas, se les solicita a los receptores que den su opinión sobre determinado producto, y pueden contribuir para la producción y difusión de esta comunicación (Thompson, 2000). El autor también comenta la posibilidad de que los nuevos desarrollos tecnológicos en la televisión pueden proporcionar un mayor control de parte de los espectadores en relación al proceso de transmisión.

Podemos notar este cambio en el control de lo que se ve cuando observamos cómo existe, actualmente, la participación del telespectador en diversos programas deportivos a través de llamadas telefónicas, programas de comunicación por Internet (correos electrónicos) y redes sociales (Twitter y Facebook). Cuando utilizan estas herramientas, los telespectadores pueden participar con preguntas, sugerencias e indicaciones de temas, contribuyendo así con los programas de televisión. Esta participación es de cierta forma un aumento del control sobre lo que se ve.

Aunque exista este tipo de participación de parte del espectador, ver un deporte por la televisión es diferente de verlo cuando se está presente en estadios y pistas, porque la visión del deporte televisado está restricta a las jugadas y escenas previamente escogidas y seleccionadas por los periodistas, productores de las informaciones e imágenes transmitidas por la televisión. En ese caso, el contenido llega ya listo para el telespectador, previamente interpretado. El uso de recursos como lentes especiales, el sonido, la música o la narración son elementos que le dan una nueva «vestimenta» al deporte. El énfasis en la competición, en la manera como los hinchas se manifiestan, en la presentación de jugadas violentas o espectaculares, indican la transformación del deporte espectáculo en un «telespectáculo» (Betti, 1998).

La televisión selecciona las imágenes y las interpreta. Propone un modelo de lo que es el deporte y de lo que es ser deportista (Betti, 2003). Eso se nota principalmente cuando vemos, por ejemplo, un juego de voleibol o fútbol por la televisión. Los narradores no comentan sólo las jugadas, sino que dicen repetidas veces cómo las jugadas son «espectaculares», «increibles», «sensacionales», cómo los jugadores son «muros», «cracks», «fenomenales», cómo «dan un espectáculo».

Ese «entusiasmo» de los periodistas con relación al deporte que se presenta en la televisión nos hace reflexionar sobre la afirmación de Bourdieu (1997) que comenta sobre una cantidad muy importante de personas que no lee ningún periódico, y que se entregó de cuerpo y alma a la televisión como única fuente de informaciones. Para la televisión, los periodistas trabajan una selección y una construcción de lo que se selecciona. El principio de esta selección es la búsqueda por lo sensacional, por lo espectacular. La televisión dramatiza: pone en imágenes un suceso y exagera su importancia, da a ese acontecimiento o a ese evento un carácter dramático.

El «elespectáculo» es una construcción social de dos niveles: primero de todo el conjunto de agentes, atletas, entrenadores, jueces etc.; $y$, segundo, de todos aquéllos que producen la reproducción de las imágenes y discursos de ese espectáculo. El mundo de la imagen, de la televisión, está dominado por las palabras, el juego se torna un discurso sobre el propio juego (Bourdieu, 1997).

Esas palabras que dominan elmundo de lasimágenes, según Bourdieu (1997), proyectan luces sobre una expresión utilizada por Umberto Eco (1984): la «habladuría». La «habladuría» sobre el deporte da la impresión de interés por el deporte, «la noción de practicar el deporte se confunde con la de hablar sobre el deporte» (Eco, 1984, p.225).
Esta expresión resume bien lo que gran parte de la programación deportiva televisiva hace. La «habladuría» cumple algunas funciones básicas, principalmente en las «mesas redondas», informativos y programas deportivos. Según Betti (2003), estas funciones son:

- Informar y actualizar: quién perdió, quién ganó, cómo está el campeonato.

- Contar la historia: cómo fueron las partidas, los mejores goles, las mejores jugadas.

- Crear expectativas: quién será el goleador del campeonato, qué equipo será campeón.

- Explicar y justificar: explica el porqué un equipo o atleta ganó o perdió la competición.

Prometer: emociones, shows de imágenes, victorias, goles.

Crear polémicas y construir rivalidades: si fue fuera de juego o no, si el juez acertó o no.

- Criticar: hablar «solamente» sobre los árbitros y jugadores, los dirigentes, la violencia.

- Comentar: cómo fue el desempeño del equipo, del jugador;

- Elegir ídolos: el genio, el fenómeno, el crack.

Y gracias a esa expectativa, rivalidad, comentarios, polémicas, explicaciones y justificaciones es que ese discurso sobre el deporte y la programación deportiva puede continuar siempre al día siguiente (Betti, 2003).

3.2. El deporte televisivo y el papel de los profesionales de Educación Física

Teniendo como base a los autores Bourdieu (1997) y Thompson (2000), los conceptos presentados aquí contribuyen para que se desarrolle algunas reflexiones en el ámbito de la formación y desempeño profesional en el área de la Educación Física. Los estudiantes de Educación Física, seres sociales que son, poseen cierta comprensión de la influencia de los medios de comunicación en la sociedad actual, así también como del deporte. Al tener acceso al conocimiento sistematizado sobre estos temas en la formación profesional podrán conseguir una actuación futura efectiva, de modo que se haga viable que los sujetos (oyentes, lectores, espectadores, telespectadores), sus futuros alumnos, desarrollen una actitud activa y reflexiva delante de los discursos, informaciones e imágenes distribuidas por los medios de comunicación.

Antes del enfoque de la televisión al deporte, esto se asociaba al naturalismo y al ocio. Los espectadores estaban presentes corporalmente en los estadios y polideportivos. Hoy, la televisión y los vídeos por Internet (como YouTube y sitios de deportes con los mejores momentos de los partidos y competiciones) vienen causando una transformación. Esa transformación se da en relación al campo de visión del espectador. Cuando presenciamos un juego o una competencia deportiva en el lugar en que ésta ocurre tenemos una visión global, elegimos hacia dónde queremos mirar, lo que queremos observar, hacemos nuestros propios análisis, pues en la mayoría de las modalidades no hay narrador, la jugada no es transmitida nuevamente dos veces, ni es posible despejar dudas. Como ya se mencionó anteriormente, con el desarrollo de las tecnologías en relación a los diferentes sitios y vídeos de Internet, si se quiere ver más allá de los programas de deportes nuestra visión se torna parcial. Vemos apenas lo que eligieron y seleccionaron ellos previamente para colocarlo al alcance del espectador.

De todos modos, el elemento principal en esta transformación es el telespectador, quien es el sujeto que está dispuesto a pagar para ver el deporte y las competiciones. (Betti, 2003). Nosotros, como telespectadores y a la vez profesionales en el área de Educación Física, necesitamos quedarnos atentos a la manera que vemos el deporte televisivo y cuánto eso nos influencia como educadores.

El deporte como espectáculo es uno de los grandes descubrimientos del siglo XX, y la T.V. ha explorado muy bien este segmento. Por ejemplo, un $80 \%$ de los intercambios internacionales de programas de televisión en Europa son de tipo deportivo. (Pardo, 1985 apud Díaz, 2005).

Algunos eventos deportivos que se convierten en interés general reúnen frente a la T.V. personas de todo tipo, y pasan a ser un modelo 
de difusión cultural. Sin embargo, lo que en verdad ocurre, es que se está vendiendo un producto televisivo de espectáculo, donde las tendencias rivales aumentan en algunos momentos del año. En España, por ejemplo, donde el principal deporte es el fútbol, la audiencia de un juego está garantizada cuando grandes equipos rivales se enfrentan. La transmisión del deporte a través de la televisión debería incentivar la práctica deportiva de jóvenes y de adultos, e iniciar el gusto por la práctica de actividades físicas de los niños (Díaz, 2005).

El deporte es el elemento primordial de la programación de muchas emisoras de televisión gracias a la gran audiencia con la que cuentan estos programas deportivos. Además, las transmisiones de grandes eventos como las de los Juegos Olímpicos, Mundiales de Fútbol, o el Tour de Francia movilizan a un gran número de personas, tanto en la práctica deportiva como a la compra de materiales y equipos para las mismas, sin que esto signifique que tales personas se conviertan en practicantes asiduos de dichos deportes (Montín, 2008).

El deporte a través de la televisión es un contenido del ocio. Marcellino (1987) afirma que es cada vez más necesaria la consideración del ocio como objeto de educación - la educación para el ocio en una sociedad orientada por la cultura de consumo. Las producciones de los medios de comunicación de masa en su conjunto, por ejemplo, son productos direccionados al consumo del gran público. La situación de la sociedad en esta fase de producción industrial y de consumo favorece la influencia de la industria cultural, que acaba generando necesidades estandarizadas para facilitar el consumo y perpetuando o dificultando la superación de la situación de conformismo.

Por eso se hace aún más necesario un proceso educativo que motive la imaginación creadora, el espíritu crítico, o sea, una educación para el ocio, sin el objetivo de crear necesidades, como así lo hace la televisión, y sí para satisfacer necesidades individuales y sociales. Y la educación formal es el canal para eso (Marcellino, 1987).

Roberto Aparici (2003), estudioso de las áreas de Educación y Comunicación, subraya la importancia de la educación en los medios de comunicación. Él cita cuatro razones fundamentales para esta necesidad:

1. La creciente influencia de los medios de comunicación en los procesos democráticos. Los ciudadanos deben ser informados sobre las elecciones y acciones de sus representantes.

2. La alta tasa de consumo de medios de comunicación, y la saturación de mensajes transmitidos por éstos. Actualmente los niños pasan más horas consumiendo estos medios que en sus actividades escolares.

3. La capacidad de los medios de comunicación para influenciar percepciones, creencias y actitudes. La escuela ha perdido su papel en la educación y en la socialización. Estos medios no sólo informan, forman y entretienen, sino ofrecen modelos de mundo, estilos de vida, modos de ver y comprender la sociedad, así como identifican patrones para la formación del ciudadano del siglo XXI. Es necesario entender estas influencias para hacernos menos dependientes de ellos.

4. La creciente importancia de la comunicación visual y de la información. El desafío de la sociedad de la información es el educar a los ciudadanos para que puedan investigar, analizar e interpretar las informaciones, de tal forma que las transformen en conocimiento.

En este sentido, es fundamental que los profesionales que actúen futuramente como profesores estén preparados para intervenir pedagógicamente junto a sus alumnos, incluyendo la educación para el ocio a la cual se refiere Marcellino (1987). Estos profesionales podrán disfrutar de manera autónoma y crítica del ocio, gracias a tener acceso al conocimiento sistematizado en la formación profesional, y a las reflexiones sobre los productos que circulan en la cultura del consumo, y, también contar con una actuación profesional futura efectiva, conjugando sentidos y significados atribuidos al deporte transmitido vía MCM.

Cuando hablamos del ocio y de una educación para el ocio no podemos olvidarnos de los contenidos culturales relacionados por Dumazedier (1980): físico, social, manual, artístico e intelectual. El profesor de Educación Física tiene un papel importante en esta educación relacionada al ocio, por eso debe dominar todos estos contenidos.

Marcellino (2000) destaca también otros puntos para la reflexión: «Al considerarse las actividades de ocio, ¿Qué entendemos por actividad y qué por pasividad? ¿Será que todo lo que se ve, todo el consumo, pertenece al campo de la pasividad?» (p.20).

Dumazedier (1980, p.257) aclara que, en sí misma, la actividad de ocio no es activa o pasiva, «pero lo será por la actitud que el individuo asuma con relación a las actividades resultantes del propio ocio».

Según Marcellino (2000), tanto la práctica como el consumo pueden ser activos o pasivos. El autor cuestiona la valorización como «inferior» $\mathrm{o}$ «superior» en relación a la participación pasiva o la práctica de una actividad. Para el autor, lo que es determinante es la actitud del individuo en relación a la práctica o al consumo. Por eso, el espectador puede ser hasta más activo que el practicante. La diferencia entre una actividad activa o pasiva no está en el género, sino en el nivel de participación de esa persona. Estos niveles pueden clasificarse en tres prácticas: elemental, que se caracteriza a través del conformismo, una repetición sin pensar en lo que se hace o se ve; mediano, en donde existe la criticidad; y superior o inventivo, cuando se usa la creatividad. Un espectador activo tendría características como «selectividad, sensibilidad, comprensión, apreciación y explicación» (Marcellino, 2000, p.2021). El objeto de «consumo» vuelve a crearse y se interpreta.

Por lo tanto, la mayoría de las críticas surge a partir de la comprensión de la televisión como consumo pasivo en el sentido de que el telespectador desconoce su valor cultural (Betti, 2003). Y en este caso, ¿cuál es el papel del profesional de Educación Física? El profesor en su educación para y por el ocio debe proporcionar a sus alumnos la oportunidad de conocer las tres prácticas citadas por Marcellino (2000) durante las actividades. Es parte integrante del profesor la motivación para que sus aprendices alcancen el nivel superior o inventivo, y cabe a ellos elegir en qué nivel desean estar.

Con el desarrollo de las técnicas de comunicación masiva (como la televisión), la producción cultural deja de alcanzar un nivel local y pasa a alcanzar un mercado consumidor mucho mayor. La gran mayoría del tiempo libre que se tiene se disfruta en las propias viviendas, dentro de las casas, lo que propicia la formación de un «público cautivo» de la televisión (Marcellino, 2000).

La comprensión de este fenómeno en la formación del profesional de Educación Física podrá capacitar a estos individuos para que tengan una intervención futura que promueva el desarrollo de la conciencia crítica y creativa por parte de los telespectadores, es decir, una intervención profesional focalizada futuramente en la educación para el ocio.

\section{Conclusiones}

Con las reflexiones desarrolladas pudimos destacar cómo se da la transmisión del deporte a través de los medios de comunicación de masa, en particular por la televisión, y vemos cómo es fundamental la actuación de los profesionales de Educación Física, papel que se centraliza en la perspectiva de la educación para el ocio, proporcionando a los individuos el acceso a conocimientos para que sean capaces de transformar la información relacionada al deporte que están conociendo.

$\mathrm{Al}$ término de esta discusión llegamos a la siguiente conclusión: Cuando el deporte es difundido por la televisión se convierte en un «telespectáculo», y es en este proceso que se hace fundamental el papel del profesional de Educación Física, quien intercederá como transmisor de sus conocimientos. El profesor de esa área, fundamentado en la perspectiva de la educación para el ocio, hará viable en sus alumnos el acceso a tal conocimiento, haciendo posible que éstos logren alcanzar un nivel superior o llamado «inventivo de comprensión». En consecuencia, la intervención pedagógica realizada en la educación formal será fundamental para que los individuos tengan acceso a elementos teóricos que les permita realizar una lectura altamente calificada del deporte difundido por los medios de comunicación gracias a contar con los requisitos necesarios para ello, y de igual manera puedan disfrutar de sus momentos de ocio con calidad. 


\section{Aplicaciones prácticas}

Este trabajo es una prestación pública de carácter asistencial para que el deporte televisivo pueda ser un tema discutido ampliamente en los cursos de formación profesional del área de Educación Física, de tal forma que pueda capacitarse a los futuros profesores para que desempeñen una actuación profesional de educación y ocio, tanto en el ámbito escolar como en la educación no formal. Esta acción profesional podría consistir en discutir y analizar con los propios estudiantes de Educación Física la transformación del deporte ofrecido a través de la televisión en un «telespectáculo», haciendo posible que dichos sujetos realicen una lectura calificada del contenido difundido por este medio.

\section{Futuras líneas de investigación}

Las reflexiones desarrolladas a lo largo de este trabajo destacan el desarrollo de estudios futuros que tengan como finalidad el identificar cómo los sujetos reciben las informaciones relacionadas al deporte (y las demás manifestaciones corporales) difundidas por los medios de comunicación de masa, o investigaciones que tengan como objetivo el seguimiento de experiencias pedagógicas realizadas dentro de lo que constituye la educación para el ocio. Tales discusiones serán, ciertamente, contribuciones para los cursos de formación profesional en Educación Física, y para la intervención del profesional de dicha área en el ámbito formal y no formal.

\section{Referencias}

Adorno, T. W. (1986). La Industria Cultural. In Cohn, G. (Ed.), Theodor W. Adorno: Sociología. Sao Paulo: Ática. Grandes Científicos Sociales.

Aparici, R. (2003). La Reinvención de la Educomunicación. In Comunicación educativa en la sociedad del la información, p. 31. Uni- versidad Nacional de Educación a distancia. Disponible en http:// www.uned.es/ntedu/asignatu/1_Roberto2.htm

Aparici, R. (2005). La Responsabilidad de la Comunicación, y de los nuevos Medios de Comunicación en el mundo globalizado. Entrevista. Dialogía, Sao Paulo, v. 4, p. 15-23.

Betti, M. (1998). La Ventana de Vídrio: El deporte, la televisión y la educación física. Campinas: Papirus.

Betti, M. (2003). La Ventana de Vidrio: El deporte, la televisión y la educación física (2da. Edición). Campinas: Papirus.

Bourdieu, P. (1983). Cómo ser deportivo. In Bourdieu, P. (Ed.), Cuestiones de Sociología. Río de Janeiro: Marco Zero.

Bourdieu, P. (1997). Sobre la Televisión. Oeiras: Celta Editora.

Díaz, J. T., \& González, J. A. R. (2005). Deporte y televisión: una perspectiva desde

la educación física escolar. Comunicar, 25. Disponible en http:// www.revistacomunicar.com/verpdf.php?numero $=25 \&$ articulo $=25$ 2005-207

Dumazedier, J. (1980). Valores y Contenidos Culturales del Ocio. Sao Paulo: SESC.

Eco, H. (1984). Viaje en la Irrealidad Cotidiana. Río de Janeiro: Nova Frontera.

Marcellino, N. C. (1987). Ocio y Educación (11Ú edición.). Campinas: Papirus.

Marcellino, N. C. (2000). Estudios del Ocio: una introducción (2da. edición.). Campinas, SP: Autores Asociados.

Marchi Junior, W. (2005). Desporto. In González, F. J.; Fensterseifer, P.E. (Eds.),Diccionario Críticode Educación Física. Ijuí:Ed.Unijuí.

Montín, J. M. (2008). Educar en el Deporte a través de la TV. Comunicar, 31, XVI, p. 517-521.

Severino, A. J. (2007). Metodología del Trabajo Científico. São Paulo: Editora Cortez.

Thompson, J. R. (2000). Ideología y Cultura Moderna: Teoría Social Crítica en la era de los Medios de Comunicación de Masa (5ta. edición.). Petrópolis: Vozes.
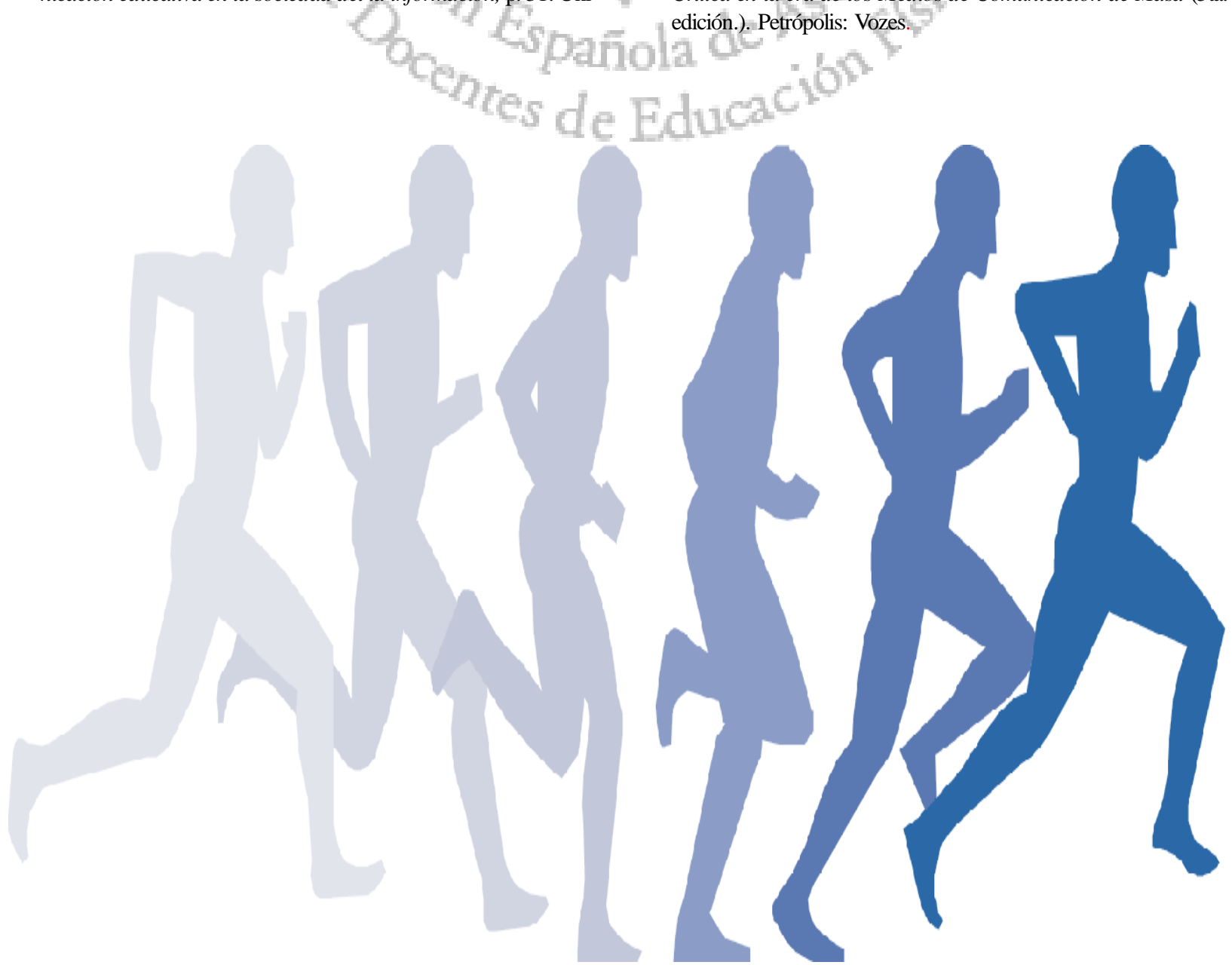